Arteterapia. Papeles de arteterapia y educación para inclusión social ISSN: $1886-6190$

\title{
Elvira Gutiérrez In Memoriam
}

\section{Carlos Olavarría García-Perrote ${ }^{1}$}

Elvira ha partido de viaje para esculpir almas en otros paisajes. Todavía con el impacto de la pérdida de esta maestra, con la que tanto compartí, de la que tanto aprendí, que tantos caminos me abrió, quiero invitaros a un pequeño "tráiler" de los muchos que se podrían "filmar" sobre ella.

Hace ya quince años la conocí. En el 2000, Noemí Martínez y Marián López Fernández-Cao, pusieron en marcha como co-directoras el Máster en Arteterapia de la Universidad Complutense. Yo, entusiasmado como estaba por el arte tanto como por la psicología, no dudé en embarcarme en aquella primera promoción. Allí, entre un profesorado comprometido, entregado y creativo, que me abrió un mundo de posibilidades de impacto sanador del arte en lo personal y lo social, no podía faltar una profesora de mirada penetrante, reflexiva y curiosa como si estuviera en una eterna pregunta que, a mí al menos, me hizo dar un salto hacia una metodología humanista que me atrajo poderosamente y que fui nutriendo a lo largo de los años para llegar a la verdad de mí mismo y de mis pacientes y alumnos.

Si nos asomamos a la historia de Elvira vemos a una apasionada artista unida a un corazón y una mente que tenían como motor una omnipresente pregunta: ¿cómo puede el arte ayudar a alguien a expresarse y a conocerse en profundidad y en ese camino encontrar alternativas más sanas y satisfactorias para su vida?

Elvira llegó como ella decía por "pura intuición” y añadía: "como es bastante característico en mí". Ella no había oído hablar de Arteterapia y a su alrededor tampoco nadie le daba noticias de que el arte pudiera estar relacionado con la vida más interna o el inconsciente del ser humano. Ella creía estar inventando "una mejor manera de enseñar a pintar" mediante la incorporación del cuerpo y las emociones, potenciando una mayor conciencia del estado físico y anímico. Y estas ideas las ponía en práctica con sus alumnos y, desde luego, con ella misma.

Al mismo tiempo empezó a formarse en Terapia Gestalt en la Escuela Madrileña y las preguntas, la ilusión y los estímulos se iban multiplicando.

Empezó a tejer una red de conceptos y experiencias: la relación entre los centros de energía y los colores que conocía a través del Yoga y, por otra parte, la de las zonas corporales y las emociones a través de la Terapia Gestalt. Fue entonces cuando esa red empezó a centrarse en los pilares fundamentales en los que se basó

1 Terapeuta Gestalt e Integrativo, Terapeuta Corporal y Arteterapeuta. 
la Escuela que crearía unos años más tarde, el entrañable Centro de Arteterapia y Gestalt, que nació en la sala de un Centro Cultural en Pozuelo de Alarcón y continuó, al tiempo humilde y poderoso, en la Calle Reina de Madrid, en la que he tenido la fortuna de acompañarle doce de esos intensos años, y donde se ha formado una magnífica legión de arteterapeutas humanistas. Esos puntos de referencia a los que me refería son el arte, las emociones y los centros energéticos o chakras. Con ellos ya estaban colocados los cimientos, y sólo tenía que ir madurando los conceptos, buceando en los antecedentes en Estados Unidos y Europa y darse el placer de hacer incursiones en las más antiguas tradiciones: persa, china, hindú, griega, cristiana, hebrea, musulmana... además de afilar esa mirada investigadora, cuestionadora, ilusionada y apasionada en sus talleres y en su propio trabajo artístico.

En el año 1997 leyó su Tesina para la Asociación Española de Terapia Gestalt: "Arteterapia. Expresión plástica, el color y los centros de energía" dirigida por Paco Peñarrubia, maestro de tantos de nosotros, y dos años más tarde su Tesis en la Universidad Complutense de Madrid "Arte-Terapia con orientación gestáltica" dirigida por Noemí Martínez Díez, entrañable, generosa y brillante investigadora, de la que tuve el placer de ser alumno. Más tarde, en el año 2011, escribió su libro: "Arteterapia Humanista. Proceso gestáltico a través de los chakras" de Mandala Ediciones. Antes tuvo un hijo y plantó muchos árboles. Disfrutó plenamente de la naturaleza en la casa que tenía en sus queridas Alpujarras donde meditaba mientras las montañas, delante de ella, cambiaban de color y hacían que de su corazón fluyeran las más profundas emociones y también las más profundas intuiciones.

España se le quedaba pequeña y viajaba para llegar a experiencias y conocimientos que aquí no encontraba, como a Italia donde pudo confirmar los efectos del color en relación con la salud, la terapia de colores, de mano de Yuji Yahiro. $\mathrm{O}$ en India donde me contaba, con su visión de entusiasta arqueóloga, que había templos con tanta energía que nada más sentarse en ellos en meditación se sentía plenamente alineada.

Disfrutó de innumerables actividades que la iban haciendo crecer y que iban también enriqueciendo su experiencia: yoga, judo, flauta, taichí, sumi-e, mandalas... Nada que tuviera que ver con la conciencia o el arte escapaba a su curiosidad.

Pero mientras tanto Elvira, tuvo que pasar por compatibilizar esta dedicación unos años con el trabajo en un banco, como muchos de los que nos hemos empeñado en dedicarnos a una profesión tan joven y desconocida hemos tenido que hacer. Son muchos los escollos que hay que atravesar para que la nave de nuestra intuición nos lleve a un paisaje en el que los pulmones puedan oxigenarse profundamente, en el que nuestras piernas se sientan fuertes y libres para sostenernos, en el que todas nuestras articulaciones y músculos bailen y nos hagan expresar el placentero balanceo de la vida, en el que nuestro pecho se expanda, sienta el latir de cada ser vivo y vibre con él. En el que nuestra garganta, nuestros brazos y nuestras manos se sientan libres para ser fuente de nuestro manantial 
interior hacia el mundo. A este paisaje llega de manera natural el arte en cualquiera de sus versiones.

Hay mucho trabajo que hacer en las Escuelas e Instituciones pero también con los responsables políticos de la cultura y la educación para que el Arteterapia pueda llegar a ser una disciplina y una profesión digna valorada y respetada por esta sociedad a la que desde hace ya muchos años está aportando tanto.

En los tiempos que corren a los que, como Elvira, nos manchamos las manos y el alma de pintura, de tinta, de barro, a los que nos emocionamos escuchando músicas de todas las culturas y con su ritmo bailamos o meditamos buscando la flexibilidad y permeabilidad de nuestro plexos... a todos nosotros, nos ve la sociedad "desconectados de la realidad". Es difícil encontrar un atisbo en los planes educativos de todas estas sanadoras disciplinas. Sin embargo, la ciencia nos está dando la razón y cada día más científicos desde la neurociencia y otras disciplinas legitiman el lugar que el cuerpo y las emociones ocupan por derecho propio.

Tomo prestadas las palabras de Mario Alonso Puig, Médico, Cirujano General y del Aparato Digestivo, Profesor y Conferenciante, para refrendar la legitimación de la ciencia a los que trabajamos con el cuerpo y las emociones al menos en la misma medida que con la mente.

"El corazón es mucho más que un órgano físico que bombea sangre. Es mucho más que eso.

El corazón a nivel biológico es un cerebro, que tiene 40.000 neuronas. Es un órgano que genera un campo magnético , 10.000 veces más potente que el cerebro y que cada vez está mostrando que puede actuar a través de esos campos electromagnéticos, a través de esos pulsos que se sienten, por lo tanto es un órgano que está transmitiendo información a cada célula del cuerpo. A cada una de las 60 trillones de células del mismo.

Entonces cuando una persona tiene un corazón oprimido, se ha cerrado a la posibilidad de querer, agradecer y perdonar. Y cuando esto se produce, en función a lo que conocemos en el día de hoy, se cierra también ciertas capacidades del cerebro, como tomar decisiones o ser creativos, pero también sabemos que daña seriamente su salud.

Así que creo que el $1^{\circ}$ objetivo que debe tener una persona en su vida es abrir ese corazón, su cabeza funcionará mejor, y sobre todo su cuerpo estará más sano".

El Arte nos impulsa la intuición, nos abre a las emociones y nos permite expresarlas apartando filtros y bloqueos, nos facilita llegar a lugares donde a la mente, bien amaestrada para no alterar la cotidianeidad de nuestras vidas, le es difícil llegar. La función del arte, desde la Prehistoria hasta hoy, toca lo sagrado, potencia la conciencia, la emoción, desbloquea los centros energéticos y favorece la plasticidad neuronal... La función del arte es más necesaria que nunca en nuestra sociedad. Tanto como personas como tú, Elvira. Y la función de los que quedamos y te conocimos es medrar en el empeño de seguir ofreciendo la "magia" del abrazo del Arte y la Terapia, que tanto ayudaste a difundir, esa magia a la que dedicaste tu vida. 
Contabas, Elvira, una paradoja zen: "El deseo de iluminación impide la iluminación, pero sin deseo ni siquiera hay búsqueda". Tú lo interpretabas así: "se trata de ponerse en disposición de estar preparado para recibir el regalo cuando llegue, si llega, y si no llega es lo mismo porque el hecho de estar preparado es en sí el regalo".

Tú Elvira, viviste así, con esa disposición, y entre las muchas cosas que aprendí de ti, hoy me quiero quedar con esta paradoja que es un espejo de tu vida y de tu legado.

Elvira ha seguido su viaje. Ojalá que las montañas que la rodeen cambien de color como las de las Alpujarras, y que su luz siga iluminando nuestro camino.

Gracias por haber pasado por aquí querida Elvira, querida maestra. 